\title{
Biomaterials and Fabrication to Optimise Scaffold \\ Properties for Musculoskeletal Tissue Engineering
}

Running title: Biomaterials and Scaffolds

Wheelton A, Mace J, Khan WS, Anand S

University of Manchester, Oxford Road, Manchester, M13 9PT, UK

Correspondence:

Mr Wasim S Khan, Clinical Lecturer, University College London Institute of

Orthopaedics and Musculoskeletal Science, Royal National Orthopaedic Hospital,

Stanmore, London, HA7 4LP, UK

Telephone number: +44 (0) 7791025554

Fax number: +44 (0) 2085703864

E-mail address: wasimkhan@doctors.org.uk 


\begin{abstract}
Tissue engineering has emerged as a promising scientific field potentially yielding in vitro developed tissue to replace degenerative or injured tissues in vivo, thus avoiding the donor site morbidity associated with reconstructive surgery. Integral to the process is the role of scaffolds and the biomaterials used to form them. This review explores the concept of scaffold based tissue engineering and design considerations. The scaffold needs to have certain mechanical and architectural properties, it needs to be biocompatible and biodegradable, and allow combination with bioactive molecules. We also discuss scaffolding techniques, different biomaterial options and fabrication technologies, and future areas of development.
\end{abstract}

Key words: Tissue engineering; bioreactors; scaffolds; biomaterials; fabrication 


\section{Introduction}

Population growth coupled with increasing life expectancy has increased the burden of orthopaedic pathology. As medical technology progresses it faces the demand of developing viable solutions to the processes of trauma and degeneration with resultant damage to biological tissues causing pain and impaired function. Current strategies of treatment encompass autografts (transplant of patients own tissue to sites of injury), allografts (transplant of tissue from one patient to another) and joint replacement procedures. Autografting is associated with donor site morbidity and restricted by the fact there is a limit to how much tissue can be taken from a donor site without compromising its function. Allografting has the inherent difficulties associated with immune system rejection and the mismatch between the number of patients and donors, and joint replacement is expensive and limited by implant survival issues.

Resultantly 'Tissue Engineering' has emerged as a 'multidisciplinary field that applies the principles of engineering and life sciences toward the development of biological substitutes that restore, maintain, or improve tissue function or a whole organ' (1-3). The essence of this field is the in vitro expansion of specific cells on porous matrices (scaffolds) to create three dimensional (3D) tissues that can be implanted into the site of tissue injury (4-6). Huge scientific interest has been attracted and research in this discipline has been myriad over the last twenty years with the seemingly unlimited possibilities it offers.

Integral to the process is the concept of the 'tissue engineering triad' composing of a) a scaffold which provides structure for tissue growth, b) a reservoir of cells to enable the development of tissue and c) growth stimulating signals (or 'bioreactors') to direct the subsequent interaction between cells and scaffold (7-9). Scaffolds are critical to the process as cells cultured in vitro form two dimensional sheets incompatible with $3 \mathrm{D}$ in vivo tissues, unless they are grown on 3D scaffolding.

A biomaterial is any substance, other than drugs, synthetic or natural in origin, which can be used for any period of time, which augments or replaces any tissue organ or function of the body. Scaffolds are therefore the biomaterial basis of tissue engineering and represent an area of intense research to develop a successful 
application of tissue engineering which has so far been unrealised. This article will offer a review into the development and use of biomaterials as scaffolds in musculoskeletal tissue engineering.

\section{Demands of a Scaffold}

The structure of natural tissues serves as a guide to the design rationale within the field. A key concept is the role of extracellular matrix (ECM) which acts as an anchorage point for the majority of cells within the tissue - effectively forming a biological scaffold supporting cell proliferation and differentiation into mature tissue. The use of biomaterial scaffolds within tissue engineering is an attempt to mimic the ECM and facilitate cell mediated tissue regeneration $(10,11)$. Resultantly the characteristics of an effective scaffold parallel those of in vivo extra cellular matrix. These will vary depending on the tissue e.g. bone (12, 13), cartilage (14), meniscus (15), ligaments and tendons $(16,17)$. The limiting factor is the diversity of types of ECM within the body and their tissue specific composition (18-20) effectively curtailing the development of a single 'best fit' scaffold. Nevertheless it has been established that scaffold biomaterials should possess key characteristics as follows:

\subsection{Mechanical and Architectural Properties}

The scaffold must have sufficient mechanical strength to maintain the structure of the tissue into which it is implanted and the ability to resist the forces the tissue is routinely exposed to in vivo. This feature must be present from the time it is implanted until remodelling has taken place. Studies have shown that not only are mechanical properties imperative for implant survival the proliferating cells exhibit mechanosensitivity with scaffold stiffness influencing which cell lineages would preferentially differentiate on them in the case of stem cells (21) and which cell types adhere in the case of mature cells (22). The challenge in this regard is ensuring that the scaffold whilst being strong exhibits sufficient porosity in its structure to facilitate vascularisation, cellular penetration and efficient transport of oxygen, nutrients and waste products akin to the ECM. Equilibrium between these two design considerations is vital to the success of the scaffold.

\subsection{Biocompatibility and Biodegradability}


Key to the process is the need for the biomaterials used as scaffold material to be immunologically compatible to avoid an excessive inflammatory response and subsequent rejection and also should have high affinity for cells to allow them to interact and adhere to the scaffold. Scaffolds are not permanent implants and as such must be designed to be degradable allowing the body to replace the structure with its own tissue specific ECM. The rate of degradation should be similar to the rate at which new matrix is produced by the regenerating tissue to avoid mechanical collapse. Degradation occurs enzymatically or hydrolytically and can be influenced by scaffold design. It has been shown that scaffolds which are completely or partially degradable exhibit improved ECM distribution in comparison to non degradable scaffolds (23).

\subsection{Manufacturing Considerations}

The scaffold should be cost effective and there should be availability of batch production to make it viable in the clinical setting. Furthermore it should be possible to make it into varying shapes and sizes as demanded and consideration should be given to how it is packaged i.e. it should be amenable to sterilisation as per other surgical implants. The endeavour to develop a material and structure which most closely displays these characteristics is what steers current research with the ultimate aim of developing a clinically useful tissue engineering derived treatment. Scaffold design and development throughout the past decade can be considered both in terms of materials used and scaffolding technique, it is pertinent to consider both in reviewing the development of scaffolds.

\section{Scaffolding Technique}

Broadly speaking there have been four techniques employed throughout the period of research that are discussed in detail below. The advantages and disadvantages of each of these techniques are outlined in Table 1.

\subsection{Pre-Constructed Porous Scaffolds}

This represents the most established and widespread technique in which cells are 'seeded' in laboratory constructed porous scaffolds. The materials used are far reaching and can be broadly classified into three categories namely natural, synthetic and composite / semi-synthetic (24) which will be reviewed later. Examples of 
naturally existing biomaterials are organic polymers including polysaccharides, inorganic ceramics such as calcium phosphates and more total constructs such as allograft derived ECM. Unfortunately despite displaying excellent biocompatibility they lack the required mechanical strength necessary for use in musculoskeletal tissue engineering. The composite biomaterials have subsequently been developed to address this short coming and are a combination of natural materials reinforced with synthetics (25) to improve mechanical strength. Synthetic biomaterials can be organic materials such as synthetic polymers like polylactic acid (PLA) and inorganic materials for example bioglass. The perceived advantage of these over natural materials is that their structure can tailored to give a wide range of mechanical and architectural possibilities, however this is somewhat negated by their lack of bicompatability inhibiting cell adhesion and proliferation on their surfaces. Again the composite materials which attempt to combine the positive properties of both have been developed to overcome this for example coating synthetic materials in collagen (26).

The technique has both strengths and weaknesses in comparison to others. As the scaffolds are constructed in vitro the mechanical and architectural properties can be manipulated to develop scaffolds displaying analogous characteristics of the tissue specific ECM it is being implanted into. The technique also affords the use of a diverse range of biomaterials and as such affords flexibility in developing an appropriately designed scaffold, tailored to the varying demands of the tissue into which it is implanted. The major weakness is the difficulty of seeding the cells onto the scaffold in vitro. Limitations in the process can lead to unevenly distributed cells throughout its structure with the resultant construct displaying heterogeneous properties.

\subsection{Cell Seeding of Allograft Derived ECM}

This technique involves removing cellular antigens from allograft (or xenograft) tissues whilst preserving the ECM to develop immunologically tolerated scaffolds to which cells are then seeded in vitro. The ECM is decellularised by a variety of techniques including freeze thaw cycles and EDTA treatment (27). The decellularised ECM can then be used to replace an equivalent tissue to its base structure (28) or to 
replace a tissue different from its native state $(7,29,30)$. Advantages of this technique include its superb biocompatibility, the potential for preserved growth factors to stimulate cell proliferation on the scaffold and guide remodelling of the damaged tissue (31). The major disadvantage is that retained cellular components may stimulate an immune response and cell seeding difficulties and sequelae as for the previous technique.

\subsection{Cell Sheets}

This technique has been developed in Japan $(32,33)$ and involves the culture of cells on a temperature responsive polymer and inducing them to produce ECM and form into sheets. This can be repeated to produce multiple single layer sheets which can be bonded together to form thicker matrix. The structure of these matrices encourages neovascularisation much more readily than cell seeded scaffolds, however its value with regards musculoskeletal tissue engineering is limited as it would be very difficult to construct ECM rich tissues (due to the small volume of ECM produced by each sheet) which are typically found in bone and cartilage $(12-14,34)$. The technique is more applicable to tissues with high cell density such as corneal epithelium (35).

\subsection{Encapsulation of Cells in Hydrogel Matrix}

The principle of this technique is to ensnare living cells within a polymeric semipermeable membrane which allows diffusion of nutrients and oxygen in and waste products out, whilst also preventing immune recognition of the encapsulated cells (36). Typically hydrogels are used which are 'cross linked polymeric networks which have the capacity to hold water within their porous structure' (37). The driving force for its development has been transplant medicine with its applications including transplant of xenogenic pancreatic islet cells (38). The theoretical advantage of this technique is that the biomaterials used, from their base state as liquid monomers can be initiated to self construct solid 3D polymer meshes, with cells encapsulated (39).Enabling the complex to be delivered by injection as a liquid to the target tissue and initiated to set into the required shape. This potentially avoids open surgical procedures. So far its applicability for musculoskeletal tissue engineering has been limited by the poor mechanical properties of hydrogels. 


\section{Biomaterial Options}

The biomaterial options which have been explored so far are broadly categorized into three groups namely, natural, synthetically derived or composite/ semi -synthetic (24). They have generally been modified for use in this domain from other established surgical uses including haemostatic agents, sutures and surgical site dressings (40). The review will focus on the established materials in these classes.

\subsection{Synthetic Materials}

The perceived advantage of this group is that they can be produced under controlled methods enabling bespoke design and producing predictable mechanical and physical properties. The most commonly used group is saturated aliphatic polyesters consisting of polylactic acid (PLA), polyglycolic acid (PGA), polylacticcoglycolide (PLGA)polycarprolactones (PCL). These polymers are degraded through hydrolytic de-esterification into monomers that are excreted via naturally occurring pathways and as such meet the demands of a biodegradable scaffold. There degradation rates and mechanical properties can be manipulated through the use of copolymers and adjusting molecular weight to satisfy the demand for specific structural characteristics for different applications. There is already emerging evidence of their successful application in tissue engineering as scaffolds for gene delivery (41) and more general applications (42). Polypropylene fumarate (PPF) is a linear polyester also with good biocompatibility and degradation parameters. It has the advantage over the other example polymers of potential use as an injectable material and has been explored as is initiated in situ to form a cross linked solid polymer. It has been explored for use in bone replacement tissue engineering (43) There are however limitations to these polymers with experimental data highlighting that they undergo bulk degradation which can lead to premature mechanical failure and the resultant degradation products can cause a strong inflammatory reaction further compromising their structure and ultimate success as a scaffold $(44,45)$. The combination of these polymers with ceramics such as hydroxyapatite is one strategy being explored to reduce the inflammatory response $(46,47)$. 
Ceramics represent a large group particularly used in bone tissue engineering. They have been used in orthopaedic implants for many years and have been shown to have excellent bone bonding properties allied with excellent biocompatibility (48). The mechanism for this bone bonding is postulated to be through the formation of a carbonated hydroxyapatite (HCA) layer on the surface of the ceramic which acts as a biological interface with host tissue (49). This property lends itself to tissue engineering applications to prevent scaffold loosening following implantation. Furthermore ceramics have been shown to encourage vascularization, foster cell adhesion, growth and differentiation to osteoblasts and support enzymatic activity favouring success as tissue engineering scaffolds. (50-52) Examples of specific ceramics used as scaffolds include $\beta$-tricalcium phosphates, hydroxyapatite, Bioglass and calcium sulphate $(12,13,53-56)$. The limitations of these materials are that they lack the desired mechanical properties needed to facilitate their use as load bearing scaffolds due to low compressive strength and fracture toughness.

\subsection{Natural Materials}

These materials represent nature-designed biological options which typically overcome the issue of bioactivity posed by synthetic polymers. Cells readily adhere to and proliferate on their surface and they are typically readily biodegradable.

Collagen represents the most widely explored natural biomaterial. It is the most copious protein in mammalian tissue and a key component of extracellular matrix found in bone, tendon and cartilage - key tissues in musculoskeletal medicine (12-17, 57). It has been shown to readily allow cellular attachment and induce chemotaxis due to the topography of its surface - a key challenge when using synthetic materials and has seen it widely used on its own or in combination with other materials in tissue engineering applications (58-60). It effectiveness has been limited by concerns regarding transmission of infective diseases, inflammatory reactions, poor mechanical properties and uncontrolled biodegradability (61), the combination of collagen with synthetic materials to form composites has characterized the response to these issues $(60,61)$.

Polysaccharides are a further group of natural biomaterials, they have the ability to form hydrogels conferring the advantages described above. A key sub group is proteogylycans which make up one of the major macromolecules in articular cartilage 
(14). Chitosan is an analog of this group and is derived from chitin which is found in arthropod skeletons. It has been shown to have bioactivity with chemoatractive properties (62) and osteoconduction and is emerging as a biomaterial option (63). Further examples include starch (64), fibrin and decellularised extracellular matrix as described above (65). Despite their bioactive advantages the natural biomaterials pose challenges during fabrication resulting in heterogeneous structures and are difficult to mass produce consistently, furthermore they have proved to lack the required mechanical properties for load bearing musculoskeletal tissue engineering applications.

\subsection{Composite / Semi Synthetic}

This is the current focus of scaffold engineering. It involves the amalgamation of differing materials into a composite structure in an attempt to overcome the characteristic deficiencies of the individual constituents - i.e. combining materials having good mechanical properties and biodegradability with those displaying bioactivity. The main areas of research are bio-ceramics (combination of synthetic polymers with ceramics), synthetic and natural polymers combined and collagen amalgamated with synthetic polymers.

Examples include collagen/hydroxyapatite composites that has been demonstrated to induce bone formation and reabsorption similar to autologous bone transplant $(59,60$, 65). PLA (polyactide-aliginate amalgam) (66) which has supported the chondroinduction of mesenchymal stem cells in vitro and collagen microsponges integrated into PGLA meshes (67).

\section{Fabrication Technologies}

This has formed a separate but equally important area of research to the choice of biomaterial. The overall goal is to create a mechanically strong and porous scaffold with a 3D structure to allow cell proliferation. The following options are the existing technologies, and their advantages and disadvantages are outlined in Table 1.

\begin{tabular}{|l|l|l|}
\hline $\begin{array}{l}\text { Different Fabrication } \\
\text { Technologies }\end{array}$ & Advantages & Disadvantages \\
\hline Solvent Casting and & Technically easy & Only creates thin sheets of \\
\hline
\end{tabular}




\begin{tabular}{|l|l|l|}
\hline Particulate Leaching & & $\begin{array}{l}\text { material } \\
\text { Solvents used can inhibit } \\
\text { cell attachment and } \\
\text { proliferation }\end{array}$ \\
\hline Textile Methods & $\begin{array}{l}\text { Technically easy } \\
\text { Can be co-spun with other } \\
\text { materials such as collagen }\end{array}$ & $\begin{array}{l}\text { Difficulties in controlling } \\
\text { pore size and rigidity of } \\
\text { the scaffold }\end{array}$ \\
\hline Phase Separation & $\begin{array}{l}\text { Better control over } \\
\text { topography and the } \\
\text { characteristics of the } \\
\text { material }\end{array}$ & $\begin{array}{l}\text { Difficulty with cell } \\
\text { survival necessitating } \\
\text { composite scaffolds or } \\
\text { combining it with other } \\
\text { fabrication methods }\end{array}$ \\
\hline Solid Freeform Fabrication & $\begin{array}{l}\text { Internal micro-structure of } \\
\text { the scaffolds can be } \\
\text { specifically controlled }\end{array}$ & $\begin{array}{l}\text { Cost } \\
\text { Long time required to } \\
\text { fabricate the scaffold }\end{array}$ \\
\hline
\end{tabular}

Table 1: Advantages and Disadvantages of different fabrication methods

\subsection{Solvent Casting and Particulate Leaching}

As a technique this involves combining the polymer biomaterial (dissolved in a solvent) with soluble particles and casting the composite into a 3D mould. The particulates are subsequently leached away via chemical reaction to create pores in the scaffold. The size of the pores can be controlled by the size of particles used (68). This technique is technically easy requiring non-specilaised equipment, however the limitations are that it can only be used to create thin sheets of material and that the solvents used can inhibit cell attachment and proliferation $(69,70)$.

\subsection{Textile Methods}

Woven and non-woven fibres can be bonded together using heat or adhesives as in fibre bonding (71) or electrospinning (72) can be used, which generates electrostatic forces to overcome surface tension of polymers to create a fibre jet. Commonly PGA and PLA are used and can be co-spun with other materials such as collagen to combine the advantages of both. Again these are relatively simple techniques but are limited by difficulties in controlling pore size and rigidity of the scaffold. PGA 
scaffolds fabricated by these techniques have been used to engineer cartilage $(14,73)$ and tendon $(16,17,74)$.

\subsection{Phase Separation}

This technique is based on changes in thermal energy to create separation of a homogenous polymer solution into a multi-phase system. With separation the solution separates into a polymer rich phase and a polymer lean phase. Subsequently solvent is extracted and this creates pores. As a result of the conditions created, the topography and the characteristics of the material can be controlled $(75,76)$. The process has been used to develop scaffolds in vitro for tissue engineering applications for bone and soft tissues $(77,78)$. Difficulties have been encountered with cell survival on scaffolds produced this way and this challenge has lead to the development of composite scaffolds using this technique and combining it with other fabrication methods in attempts to make them viable $(79,80)$.

\subsection{Solid Freeform Fabrication / Rapid Prototyping}

Computer data including computer aided design, CT and MRI data is used to create custom designs of 3D scaffolds using a variety of techniques such as 3D printing, selective laser sintering and stereolithography $(81,82)$. This technique is increasing in popularity as the internal micro-structure of the scaffolds can be specifically controlled - giving precise pore size, geometry and orientation allowing bespoke designs encouraging specific cell adhesion and propagation. The major limitations of the technique are the cost and the long time required to fabricate the scaffold compared to other techniques.

\section{Combination with Bioactive Molecules}

Both scaffold architecture and material can influence how scaffolds interact with cells an important consideration as explored above. An emerging further technique to improve bioactivity is to incorporate biologically active molecules into their structure $(83,84)$. The leading examples are through growth factor inclusion (85-88) and gene delivery (86) with the aim of influencing cell proliferation, differentiation, migration and gene expression to encourage tissue regeneration. 


\section{Current Status and Future Areas of Development}

The review has summarised the current options available in terms of technique, biomaterial options and fabrication technologies. The plethora of existing options represents the myriad attempts to design a suitable bioactive scaffold that can be used clinically. The challenge is to balance the demands of required mechanical strength with architecture which has cell permissive internal structure and is sympathetic to the cellular response of the host tissue providing a suitable environment for tissue regeneration. So far the literature demonstrates very few examples of scaffolds that have been used clinically, spinal surgery has seen examples of scaffolds used in vivo with combination of recombinant human bone morphogenic protein-2 (rh BMP-2) with hydroxyapatite and tricalcium phosphate for spinal fusion with apparent success (87). Other examples exist on the market with limited data for example OSIGRAFT (Stryker) combining rhBMP-7 in a in a bovine collagen scaffold is indicated for delayed union of tibial fractures (88). Regarding systems designed for soft tissue structures treatment of rotator cuff tears has already seen scaffold based products implanted and tested. The results demonstrate no improvement in healing compared to standard treatment approaches highlighting the difficulties still faced in developing successful tissue engineering treatments $(89,90)$.

Research continues en-mass to develop the ideal material for scaffold applications with particular attention being paid to vascularisation strategies (91) bio-instructive and stimuli-responsive properties (92) and as delivery systems for growth factors and cytokines $(92,93)$ all factors which are increasingly being recognised as crucial to the survival, integration and ultimately success of scaffold based tissue engineered implants.

\section{Conflicts of Interest}

None

\section{Acknowledgements}

None 



\section{$\underline{\text { References }}$}

1. Langer R, Vacanti JP . Tissue Engineering. Science 1993; 260: 920-6

2. Khan WS, Malik AA, Hardingham TE. Stem cell applications and tissue engineering approaches in surgical practice. J Periop Pract. 2009; 19(4): 130-135.

3. Mahapatra A, Khan WS. Tissue Engineering in Orthopaedics and Musculoskeletal Sciences. Open Orthop J. 2011; 5: 239.

4. Kosuge D, Khan WS, Haddad B, Marsh D. Biomaterials and scaffolds in bone and musculoskeletal engineering. Curr Stem Cell Res Ther. 2013; 8(3): 185-191.

5. Caudwell M, Crowley C, Khan WS, Wong JM. Systematic review of preclinical and clinical studies on scaffold use in knee ligament regeneration. Curr Stem Cell Res Ther. 2014; 10(1): 11-8.

6. Crowley C, Wong JM, Fisher DM, Khan WS. A systematic review on preclinical and clinical studies on the use of scaffolds for bone repair in skeletal defects. Curr Stem Cell Res Ther. 2013; 8(3): 243-252.

7. Oragui E, Nannaparaju M, Khan WS. The Role of Bioreactors in Tissue Engineering for Musculoskeletal Applications. Open Orthop J. 2011; 5: 267 270.

8. Thanabalasundaram G, Arumalla N, Tailor HD, Khan WS. Regulation of differentiation of mesenchymal stem cells into musculoskeletal cells. Curr Stem Cell Res Ther. 2012; 7(2): 95-102.

9. Mabvuure N, Hindocha S, Khan WS. The role of bioreactors in cartilage tissue engineering. Curr Stem Cell Res Ther. 2012; 7(4): 287-292.

10. Agrawal CM, Ray RB. Biodegradable polymeric scaffolds for musculoskeletal tissue engineering. Journal of Biomedical Materials Research 2001; 55: 141-150

11. Sachlos E, Czernuszka JT. Making tissue engineering scaffold work: review on the application of SFF technology to the production of tissue engineering scaffolds. European Cells and Materials 2003; 5: 29-40

12. Shekkeris AS, Jaiswal PK, Khan WS. Clinical applications of mesenchymal stem cells in the treatment of fracture non-union and bone defects. Curr Stem Cell Res Ther. 2012; 7(2): 127-133.

13. Chimutengwende-Gordon M, Khan WS. Advances in the use of stem cells and tissue engineering applications in bone repair. Curr Stem Cell Res Ther. 2012; 7(2): 122-126.

14. Punwar S, Khan WS. Mesenchymal Stem Cells and Articular Cartilage Repair: Clinical Studies and Future Direction. Open Orthop J. 2011; 5: 296.

15. Tucker B, Khan W, Al-Rashid M, Al-Khateeb H. Tissue Engineering for the Meniscus: A Review of the Literature. Open Orthop J. 2012; 6: 348-51.

16. Yates EW, Rupani A, Foley GT, Khan WS, Cartmell S, Anand SJ. Ligament tissue engineering and its potential role in anterior cruciate ligament reconstruction. Stem Cell Int. 2012: 438125.

17. Dheerendra SK, Khan WS, Singhal R, Shivarathre DG, Pydisetty R. Anterior Cruciate Ligament Graft Choices: A Review of Current Concepts. Open Orthop J. 2012; 6: 281-286.

18. Robert L. Matrix Biology: past, present and future. Pathol Biol (Paris) 2001; 49(4): 279-283 
19. Poole AR, Kojima T, Yasuda T, Mwale F, Kobayashi M, Laverty S. Composition and structure of articular cartilage; a template for tissue repair (review) Clin Orthop Related Res. 2001; 391 (Supp): S26-S33

20. Uitto J, Olsen DR, Fazio MJ. Extracellular matrix of the skin: 50 years of progress. J Invest Dermatol. 1989; 92 (4 Suppl):61s-77s

21. Engler AJ, Sen S, Sweeny HL, Discher DE. Matrix elasticity directs stem cell lineage specification. Cell 2006;126:677-689

22. Discher DE, Janmey P, Wang YL. Tissue cells feel and respond to the stiffness of their substrate. Science 2005;310:1139-1143

23. Bryant SJ, Ansenth KS. Controlling the spatial distribution of ECM components in degradable PEG hydrogels for tissue engineering cartilage. J Biomed Mater Res A 2003; 64: 70-9

24. Griffith LG. Emerging design principles in biomaterials and scaffolds for tissue engineering. Annals of the New York Academy of Sciences 2002; 961: 83-95

25. Boccaccini AR, Blaker JJ. Bioactive composite materials for tissue engineering scaffolds. Expert Rev Mec Devices 2005; 2(3): 303-317

26. Brodie JC, Goldie, E, Connel G, Merry J, Grant MH. Osteoblast interactions with calcium phosphate ceramics modified by coating with type 1 collagen. J Biomed Mater Res A 2005; 73(4): 409-421

27. Gilbert TW, Sellaro TL, Badylak SF. Decellularization of tissues and organs. Biomaterials. 2006; 27(19):3675-3683

28. Schmidt CE, Baier JM. Acellular vascular tissues: natural biomaterials for tissue repair and tissue engineering. Biomaterials 200; 21(22):2215-2231

29. Hoddle J. Extracellular matrix as a bioactive material for soft tissue reconstruction. ANZ J Surg. 2006;76(12):1096-1100

30. Fiala R, Vidlar A, Vrtal R, Belej K, Student V. Porcine small intestinal submucosa graft for repair of anterior urethral strictures. Eur Urol. 2007;51(6):1702-1708

31. Badylak SF. Xenogeneic extracellular matrix as a scaffold for tissue reconstruction. Transpl IMMUNOL. 2004;12(3-4):367-377

32. Okano T, Yamada N, Okuhara M, Sakai H, Sakurai Y. Mechanism of cell detachment from temperature-modulated, thydrophilic-hydrophobic polymer surfaces. Biomaterials 1995;16(4):297-303

33. Takezawa T, Mori Y, Yoshizato K. Cell culture on a thermo-responsive polymer surface. Biotechnology(NY) 1990;8(9):854-856

34. Yang J, Yamato M, Shimzu T, Sekine H, Ohashi K, Kanzaki M, Ohki T, Nishida K, Okano T. Reconstruction of functional tissues with cell sheet engineering. Biomaterials 2007;28(34):5033-5043

35. Nishida K, Yamato M, Hayashida Y, Watanabe K, Yamamoto K, Adachi E, Nagai S, Kikuchi A, Maeda N, Watanabe H, Okano T, Tano Y. Corneal reconstruction with tissue-engineered cell sheets composed of autologous oral mucosal epithelium. N Eng J Med 2004; 351 (12):1187-1196

36. Lanza RP, Hayes JL, Chick WL. Encapsulated cell technology. Nat Biotechnol 1996;14(9):1107-1111

37. Pal K, Banthia AK, Majumdar DK. Polymeric hydrogels: characterization and biomedical applications - a mini review. Designed monomers and polymers 2009; 12: 197-220 
38. Gray D. An Overview of the immune system with specific reference to membrane encapsulation and islet transplantation. Ann NY Acad Sci 2001;944:266-239

39. Nguyen KT, West JL. Photopolymerizable hydrogels for tissue engineering applications. Biomaterials 2002; 23 (22):4307-4313

40. Lee D, Ansell C. Emeging applications for biomaterials in tissue engineering. MD Technology Watch Series. Article 3.2003

41. Luu YK, Kim K, Hsiao BS, Chu B, Hadjiargyrou M. Development of a nanostructured DNA delivery scaffold via electrospinning of PLGA and PLA-PEG block co-polymers. Journal of controlled release 2003; 89(2):341353

42. Burkersroda FV, Schedl L, Gopferich A. Why degradable polymers undergosurface erosion or bulk erosion. Biomaterials 2002; 23(21):42214231

43. Peter SJ, Lu L, Kim DJ, Mikos AG. Marrow stromal osteoblast function on a polypropylene fumarate/ Btricalcium phosphate biodegradable orthoapedic composite. Biomaterials 2000; 21: 1207-1213

44. Bergsam EJ, Rozema FR, Bos RRM, Debruijin WC. Foreign body reaction to resorbable polylactic bone plates and screws used for the fixation of unstable zygomatic fractures. J Oral Maxillofac Surg 1993; 51:666-70

45. Anderson JM. Biological responses to materials. Annual Review of Materials Resaerch 2001; 31: 81-110

46. Kempen DHR, Lu L, Kim C, Zhu X, Dhert WJA, Currier BL, Yasemski MJ. Controlled drug release from a novel injectable biodegradable microsphere/scaffold composite based on polypropylene fumarate. Journal of Biomedical Materials Research 2006; 77A: 103-111

47. Andrew SD, Phil GC, Marra KG. The influence of polymer blend composition on the degradation of polymer/hydroxyapatite biomaterials. $\mathrm{J}$ Mater Sci: Mater Med 2001;12: 673-7

48. Hench LL, Splinter RJ, Allen WC. Bonding mechanisms at the interface of ceramic prosthetic materials. J Biomed Mater Res Symp 1971;2: 117-41

49. Hench LL. Bioceramics: from cocept to clinic . J AM Ceram Soc 1991; 74:1487-1510

50. Day RM, Boccaccini AR, Shurey S, Roether JA, Forbes a, Hench LL. A ssessment of polyglycolic acid mesh and bio-active glass for soft tissue engineering scaffolds. Biomaterials 2004; 25: 5857-66

51. Gatti AM, Valdre G, Oh A. Analysis of the in vivo reactions of a bioactive glass in soft and hard tissue. Biomaterials 1994; 15: 208-12

52. Roether JA, Gough JE, Boccaccini AR, Hench LL, Maquet V, Jerome R. Novel bioresorbable and bioactive composites base on bioactive glass and polyactide foams for bone tissue engineering. J Mater Sci- Mater Med 2002;13:1207-14

53. Van der Pol U, Mathieu L, Zeiter S, Bourban PE, Zambelli PY, Pearce SG. Augmentation of bone defect healing using a new biocompatible scaffold: an in vivo study in sheep. Acta Biomaer 2010; 6: 3755

54. Li J, Li Y, Ma S, Gao Y, Zuo Y, Hu J. Enhancement of bone formation by BMP-7 transduced mSCs on biomimetic nano-hydroxyapatite/polyamide composite scaffolds in repair of mandibular defects. J Biomed Mater Res A 2010;95: 973 
55. Xynos ID, Hukkanen MVJ, Buttery LDK, Hench LL, Polak JM. Bioglass 45S5 stimulates osteoblast turnover and enhances bone formation in vitro; implications and applications for bone tissue engineering. Calcif Tissue Int 200; 67:321-9

56. Gao C, Huo S, Li X, You X, Zhang Y, Gao J. Characteristics of calcium sulphate/gelatine composite biomaterials for bone repair. J Biomaet Sci Polym Ed 2007; 18; 799.

57. Lee KY, Peters MC, Anderson KW, Mooney DJ. Controlled growth factor release from synthetix extracellular matrices. Nature;408: 998-1000

58. Taylor PM, Cass AEG, Yacoub MH. Extracellular matrix scaffolds for tissue engineering heart valves. Progress in paediatric cardiology 2006; 219-225

59. P Mafi, S Hindocha, R Mafi, W S Khan. Evaluation of biological proteinbased collagen scaffolds in cartilage and musculoskeletal tissue engineeringA systematic Review of the Literature. Curr Stem Cell Res Ther. 2012; 7(4): 302-309.

60. Kikuchi M, Ikoma T, Itoh S, Matsumoto HN, Koyama Y, Takakuda K, Shinomiya K, Tanaka J. Biomimetic synthesis of bone like nanocomposites using self-organization mechanism of hydroxyapatite and collagen.

Composite Science and Technology 2004; 64: 819-825

61. Ma L, Gao CY, Mao ZW, Zhou J, Shen JC. Enhanced biological stability of collagen porous scaffolds by using amino acids as novel cross linking bridges. Biomaterials 2004; 25: 2997-3004

62. Usami Y, Okamoto Y, Minami S, Matsuhashi A, Kumazawa NH, Tanioka S, Shigemasa Y. Chitin an chitosan induce migration of bovine polymorphonuclear cells. J Vet Med Sci 1994; 56(4):761-2

63. Zhao F, Yin YJ, Lu WW, Leong JC, Zhang W, Zhang JY, Zhnag MF, Yao KD. Preparation and histological evaluation of biomimetic threedimensional hydroxyapatite/chitosan-gelatin network composite scaffolds. Biomaterials 2002; 23:3227-3234

64. Lam CXF, Mo XM, Teoh SH, Hutcmacher DW. Scaffold development using 3D printing with a starch based polymer. Materials Science and Engineering 2002; 20: 49-56

65. Gleeson JP, Plunkett NA, O'Brien FJ. Addition of hydroxyapatite improves stiffness, interconectivity and osteogenic potential of a highly porous collagen bases scaffold for bone tissue regeneration. Eur Cells Mater 2010; 20: $218-230$

66. Caterson EJ, Nesti LJ, Li WJ, Danielson KG, Albert TJ, Vaccaro AR, Tuan AS. Three-dimensional cartilage formation by bone marrow-derived cells seeded in polyactide/aliginagte amalgam. J Biomed Mater Res 2001; 57(3):394-403

67. Chen G, Liu D, Tadokoro M, Hirochika R, Ohgushi H, Tanaka J, Tateishi T. Chondrogenic differentiation of human mesenchymal stem cells cultured in a cobweb-like biodegradable scaffold. Biochem Biophys Res Commun 2004; 322(1):50-5

68. Liao CJ, Chen CF, Chen JH, Chiang SF, Lin YJ, Chang KY. Fabrication of porous biodegradable polymer using a solvent merging/particulate leaching method. J Biomed Mater Res 2002; 59(4): 676-81

69. Miko AG, Temenoff JS. Formation of highly porous biodegradable scaffolds for tissue engineering. EJB Electronic Journal of Biotechnology 2000; 13(2): 114-119 
70. Chen MK, Badylak SF. Small bowel tissue engineering using small intestinal submucosa as a scaffold. Journal of Surgical Resaerch 2001; 99: 352-358

71. Cooper JA, Lu HH, Ko FK, Freeman JW, Laurencin CT. Fiber-based tissueengineered scaffold for ligament replacement; design considerations and in vitro evaluation. Biomaterials 2005; 26: 1523-1532

72. Ouyang HW, Goh JC, Thambyah A, Teoh SH, Lee EH. Knitted polylactide-go-glycolide scaffold loaded with bone marrow stromal cells in repair and regeneration of rabbit achilles tendon. Tissue Engineering 2003; 9(3): 422-431

73. Vacanti CA, Langer R, Schloo B, Vacanti JP. Synthetic polymers seeded with chondrocytes provide a template for new cartilage formation. Plat Reconstr Surg 1991; 88:753-759

74. Cao Y, Yongtao JP, Ma X. Generation of neo-tendon using synthetic polymers seeded with tenocytes. Trasplant Proc 1994; 26: 3390

75. Chen GP, Ushida T, Tateishi T. Dveelopment of biodegradable porous scaffolds for tissue engineering. Materilas Science and Engineering 2001; 17: 63-69

76. Ma P, Zhang R. Synthetic nano-scale fibrous extracellular matrix. Journal of Biomedical Materials Research 1999; 46:60-72

77. Blaker JJ, Gough JE, Maquet V, Nothinger I, Boccaccini AR. In vitro evaluation of novel bioactive composites based on Bioglass-filled polyactide foams for bone tissue engineering scaffolds. J Biomed Mater Res A 2003; 66A: $335-46$

78. Verrier s, Blaker JJ, Maquet V, hench LL, Boccaccinine AR. PDLLA/BIoglass composites for soft tissue and hard tissue engineering: an in vitro cell bilogy assessment. Biomaterials 2004; 25: 3013-21

79. Liu X, Ma P. Seperation, pore structure, and properties of nanofibrous gelatine scaffolds. Biomaterials 2009; 30: 4094-4103

80. Liu X, Smith L, Hu J, Ma P. Biomimetic nanofibrous gelatin/apatite composie scaffolds for bone tissue engineering. Biomaterials 2009; 30: 2252-2258

81. Dhariwala B, Hunt E, Boland T. Rapid prototyping of tissue engineering constructs, using photopolymerizable hydrogels and sterolithography. Tissue Eng 2004; 10(9-10): 1139-1143

82. Hutchmacher DW, Sittinger M, Risbud MV. Scaffold-based tissue engineering: rationale for computer-aided design and solid freeformfabrication systems. Trends Biotechnol 2004; 22(7): 354-362

83. Fisher DM, Wong JM, Crowley C, Khan WS. Preclinical and clinical studies on the use of growth factors for bone repair: a systematic review. Curr Stem Cell Res Ther. 2013; 8(3): 260-268.

84. M Kanitkar, HD Tailor, WS Khan. The Use of Growth Factors and Mesenchymal Stem Cells in Orthopaedics. Open Orthop J. 2011; 5:271.

85. Richardson TP, Peter MC, Bennet AB, Mooney DJ. Polymeric system for dual growth factor delivery. Nat Biotechnol 2001; 19: 1029-34

86. Luu YK, Kim K, Hsiao BS, Chu B, Hadrjiagryou M. Development of a nanostructured DNA delivery scaffold via electospinning PGLA and PLAPEG block copolymers. Journal of Controlled Release 2003; 89(2): 341-353 
87. Boden SD, Kang J, Sandhu H, Heller JG . Use of recominent human bone morphogenic protein- 2 to achieve posterolateral lumbar fusion in humans: a prospective randomised clinical pilot trial. Spine 2002; 27: 2662

88. Deloye C, Suratwala SJ, Cornu O, Lee FY. Treatment of allograft non unions with recombinant human bone morphogenic protein (rhBMP). Acta Orthop Belg 2004; 70 : 2004

89. Castricini R, Longo UG, De Benedetto. Platelet rich plasma augmentation for srtroscopic rotator cuff repair; a randomized controlled trial. Am J Sports Med 201; 39: 2

90. Rodeo SA, Delos D, Williams RJ, Adler RS, Pearle A,Warren RF: The effect of platelet-rich fibrin matrix on rotator cuff tendon healing: A prospective, randomized clinical study. Am J Sports Med 2012;40(6):12341241

91. Phelps E, Garcia A. Engineering more than a cell: vascularisation strategies in tissue engineering. Current Opinion in Biotechnology 2010; 21: 704-709

92. Place E, Evans N, Stevens M. Complexity in biomaterials for tissue engineering. Nature Materials 2009: 8: 457-470

93. Taylia P, Monney DJ. Controlled growth factor delivery for tissue engineering. Adv Mater 2009; 21(32-33): 3269-85 